\title{
SOME STATISTICS OF THUNDER AND LIGHTNING AT KIMBERLEY.
}

By J. R. Sutron.

The annexed Tables I, II, III, give summaries of the results of eye and ear observations of thunder and lightning made at Kimberley during the twentythree years 1897 to 1919 . They show, month by month, the duration of all the lightning seen, and of thunder heard, in the period. Division by twentythree would give monthly means, but, in order to save decimal places, this has not been thought necessary. The numbers given in the tables must err in defect somewhat, since it cannot be that all lightning occurring has been seen, and all thunder heard, particularly during the hours between miduight and sunrise. The error, so far as thunderstorms are concerned, cannot amount to many hours, however, and certainly not by enough to displace the times of maximum and minimum.

Table I shows that thunder and lightning together, shortly thunderstorms, have a well-marked maximum a few hours before sunset in the warm months, and a few hours after sunset in the colder ones. The intermediate months show a telldency to a double maximum, one before and one after sunset. Moreover in July the diurnal variation tends to vanish altogether; while there is some evidence of a winter maximum some time between sunrise and noon.

The totals for the year show a maximum about 4 p.m. But this might be an illusory effect, seeing that the annual totals are made up for the most part of the large summer totals. For the purpose of eliminating the exaggerated effect of the summer numbers, the last column ("weighted year") has been computed. 'This column postulates an equal duration, i. e. 266 hours, of thunderstorm for each month, the hourly totals being reduced accordingly. The issue lessens the annual totals between noon and sunset, and enlarges the others, leaving the time of maximum unaltered. It also emphasises the influence of the winter maximum after sunrise.

Table II gives statistics of the duration of lightning without thunder seen during the same period. The numbers between midnight and sunset cannot claim much for themselves: first, because there was no systematic watch set between midnight and sunrise; and next because "sheet" lightning is not usually visible in daylight, only coming into view when the luminosity of the sky becomes less than that of the discharge. 
Taking Table II as it stands, we have a maximum in each month about two hours after sunset. Now so-called sheet lightning is generally regarded as the reflection of distant thunderstorms. There is much to be said for the idea. On the other hand, since thunderstorms begin to decline in frequency before sunset, one would hence have expected, in view of the shortness of Kimberley twilight, the maximum to fall a little earlier than it appears to do. We should, indeed, anticipate a maximum as soon as the fading twilight glow would allow the lightning to be easily seen. And for more reason, that my sunshine charts are changed every day during civil twilight, and advantage is taken of the opportunity to search the horizon for lightning.

Another curious feature in the table is the greater relative rapidity with which the frequency of lightning runs down after about 8 p.m. as compared with the frequency of thunderstorms. Such a falling off depends in the main, no doubt, on the circumstance that Kimberley thunderstorms travel generally west to east.

Tables I and II are combined together in Table III. The total duration is 7130.5 hours; i.e. rather less than 1 hour in 29 , on the average, has lightning or thunder or both together. In January the frequency rises to nearly 1 hour in 15 .

At the foot of Table $I$ is given the number of nil months, that is to say the number of months without thunderstorms in the period of twenty-three years. It may be gathered from this that a month without some sort of a thunderstorm is not to be expected in the summer half-year, October to March. The winter half had thirty-nine thunderstorms between them, practically every alternate $J$ uly being free.

The next two lines in Table I show the greatest and least frequency in hours of thunderstorm weather in any one month of the period. March heads the list with $52 \cdot 5$ hours (in 1908), never falling below $7 \cdot 3$ hours (in 1902). No June, on the other hand, ever had more than 6 hours.

The next line shows the percentage of thunderstorm to the whole electric disturbance observed, as given in Table III. The great peculiarity here is the sudden rise in the thunderstorm ratio from May to June. It may be suggested as a fair inference either that the early winter thunderstorms overspread a greater area of country than the late autumn ones do; or (less likely) that they are local squalls which especially favour Kimberley. The local character of summer thunderstorms is well known. One of the most curious in my own recollection was a solitary large cloud, distant to the south-west of Kimberley, from three points of which rain, accompanied by lightning, was falling.*

The last line shows, in modern notation, the time of sunset for the

* Cf. an account in the 'Meteorologieal Magazine' for Mareh, 1920, quoted from "The 'Times,' of Central African thunderstorms observed from mid-air: "I have seen as many as a dozen of these storms [? at once] within an area of 100 square miles." 
middle of each month. The first two digits stand for the hour, the second two for the minute. Thus, for January, "1854" means $18 \mathrm{hr}$. 54 min.that is, 6.54 p.m.

The footlines in Table II are to be interpreted in the same way. The summer half shows one month (January, 1897) with no lightning observed. It is the first month of the observation period; and consequently there may be some reason to question the vigilance of the lookout. March again leads the list with a maximum duration amounting to $62 \cdot 2$ hours (in 1899) and a minimum of 7.5 hours (in 1915).

Kimberley thunderstorms are not confined characteristically to any state of barometric pressure, high or low. Statistics for five years give the following comparative numbers of these storms :

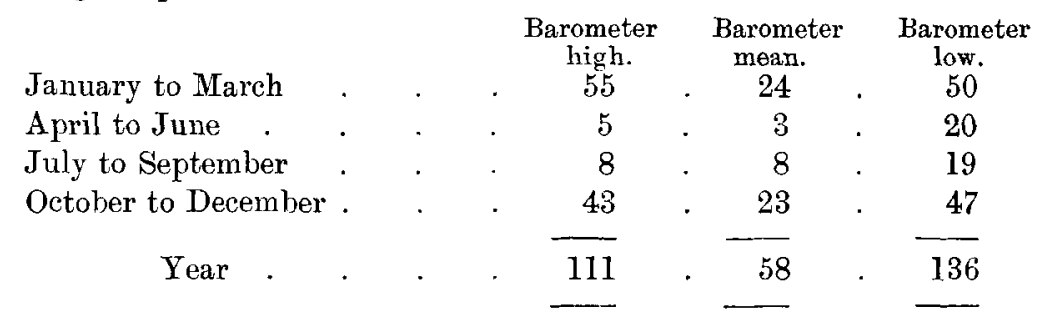

Hence in winter the few there are occur mostly with low pressures, whereas in the summer the barometric height is immaterial. What generally does happen in conjunction with the typical afternoon thunderstorm is a greater than normal fall of pressure from the morning maximum to the afternoon mimimum, as well as considerable and rapid variation while the storm is in progress.

Since the bulk of the rain on the South African Table-land falls in thunderstorms, Table IV is added for purposes of comparison. It gives the number of rainfall hours in the same observation period, 1897 to 1919. This is not to be interpreted as duration in the strict sense; but as the number of term hours in which rain was recorded, irrespective of whether it rained for each whole hour continuously, or only for a few minutes in each hour. Table IV agrees in its general features with Table I, albeit the turning points of its annual curve lag somewhat after those of the weighted annual curve of thunderstorms. There is a definite maximum of frequency about 4 p.m., and a definite minimum before noon. March has the highest frequency, August the lowest. The highest frequency in any one month goes to Jauuary, 1898, with 116 hours, for nearly $8 \frac{1}{2} \mathrm{in.} \mathrm{of} \mathrm{rain.} \mathrm{During}$ the whole observation period only one month (November, 1897) in the summer half had no rain at all, and only nineteen in the winter half had none. The statements one often sees in South African newspapers: " no rain for more than a year," "no rain for the last eighteen months," and so on, are untruths, although the cycle makers find them useful. 
At the foot of Table IV will be found the total rainfall by months; from which we deduce the average fall per hour of rain given in the following line. Rain tends to fall heaviest in February. It falls lighter in October than in any other of the seven months September to March. This is of course due to the peculiarity of Kimberley rain-as yet unexplained-that a fall exceeding an inch a day in October is uncommon. 'The only heavy falls per twenty-four hours from 1897 to 1919 have been: In October, 1902, 1.05 in.; in October, 1906, 1.56 in.; in October, 1915, 1.14 in.; in October, 1918, 1.17 in.

There are records of heavier falls than these, in one day, in most of the other months.

The following table shows the monthly percentages of-

(1) day thunderstorms to night ones;

(2) day rain hours to night ones ;

(3) day rainfall to night;

"day" being counted from 8 a.m. to 8 p.m., and " night" from 8 p.m. to 8 a.m.

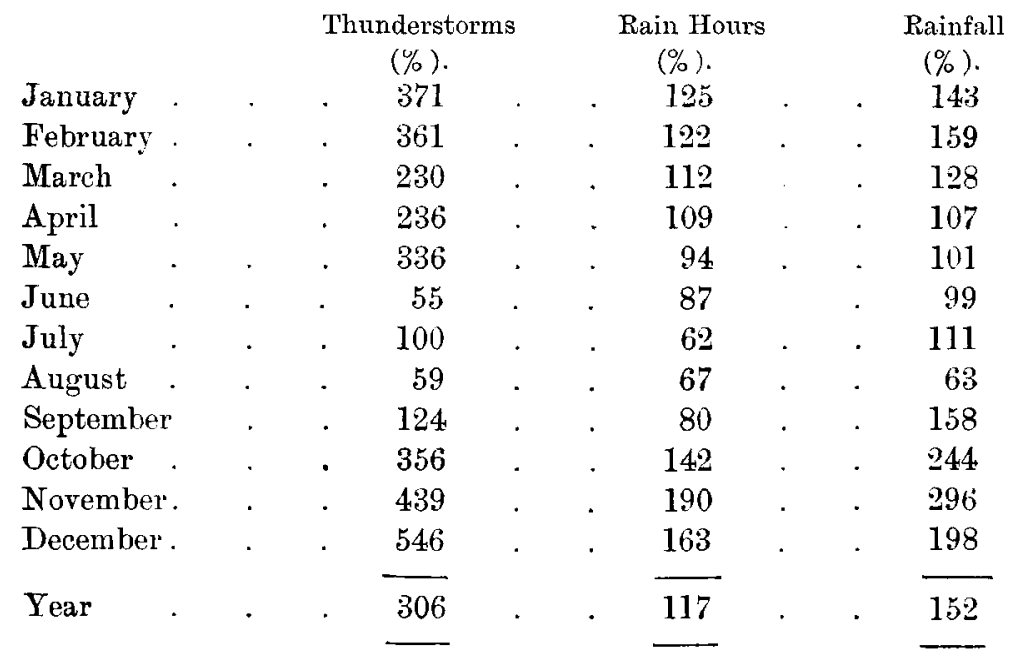

We see from this that it rains more often by day in the summer at Kimberley, and more often by night in the winter. But the total fall in the winter is on the whole about the same night or day; so that with the exception of August the rate of fall is always greater during the day: At midwinter, also, thunderstorms favour the night hours.

On the average of the year, for every hour of night rain the fall is $\cdot 044$ inch, and there is 235 hour of thunderstorm; while for every hour of day rain the fall is $\cdot 057$ inch, and 616 hour of thunderstorm-not forgetting that the hour of rain is not the duration, whereas the hour of thunderstorm is. 
Von Bezold and others have found that high temperatures produce years with abundant thunderstorms. The idea is not new ; and it is in fact stated almost in so many words in the Anglo-Saxon Manual of Astronomy :"Swa hattra sumor swa mara junor J liget on geare." For that matter neither is it generally true. At any rate it is not true for Kimberley, where much rain, and therefore many thunderstorms, signify cooler weather. The following table gives the hourly mean temperatures of January arranged in order of magnitude, together with the total duration of thunderstorms, and of lightning without thunder, for the 20 years 1900 to 1919 .

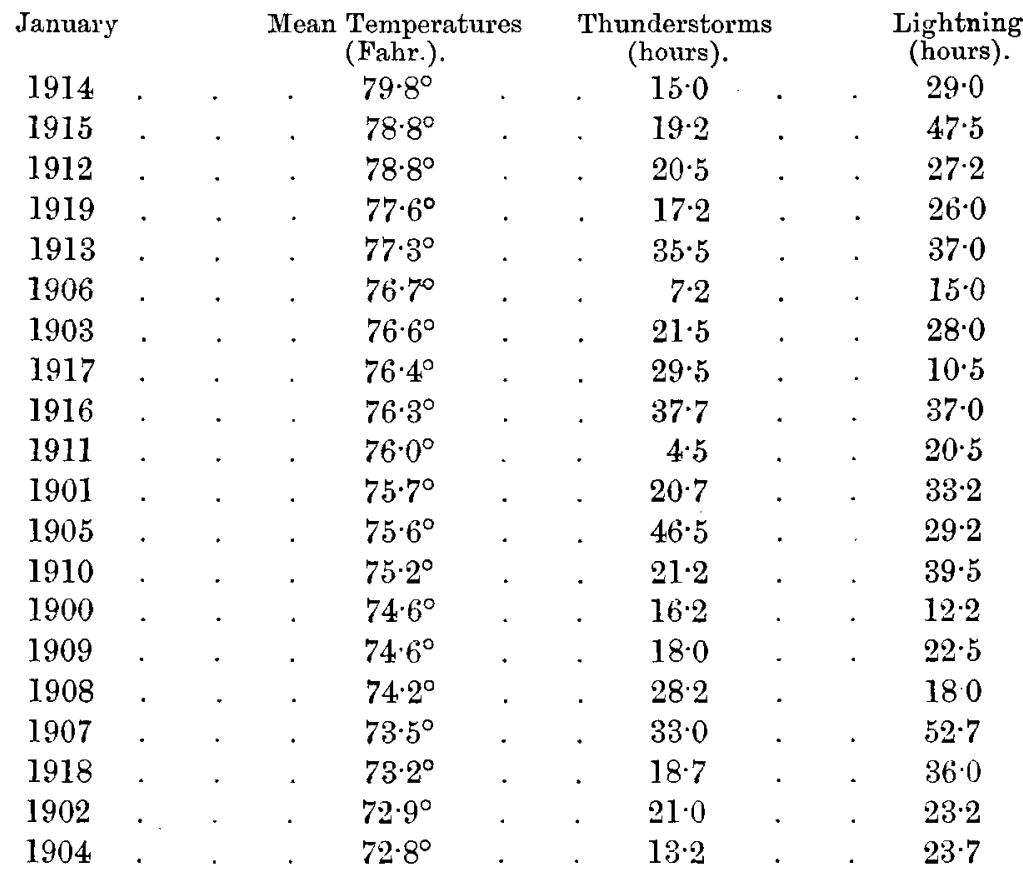

From which we deduce for January mean temperatures above $75 \cdot 9^{\circ}$ :

Mean Thunderstorm duration .
" Lightning "
" Total

The present essay was not intended to be more than statistical, compiled as a contribution to the meteorology of the Table-land of South Africa, and 
110 Transactions of the Royal Society of South Africa.

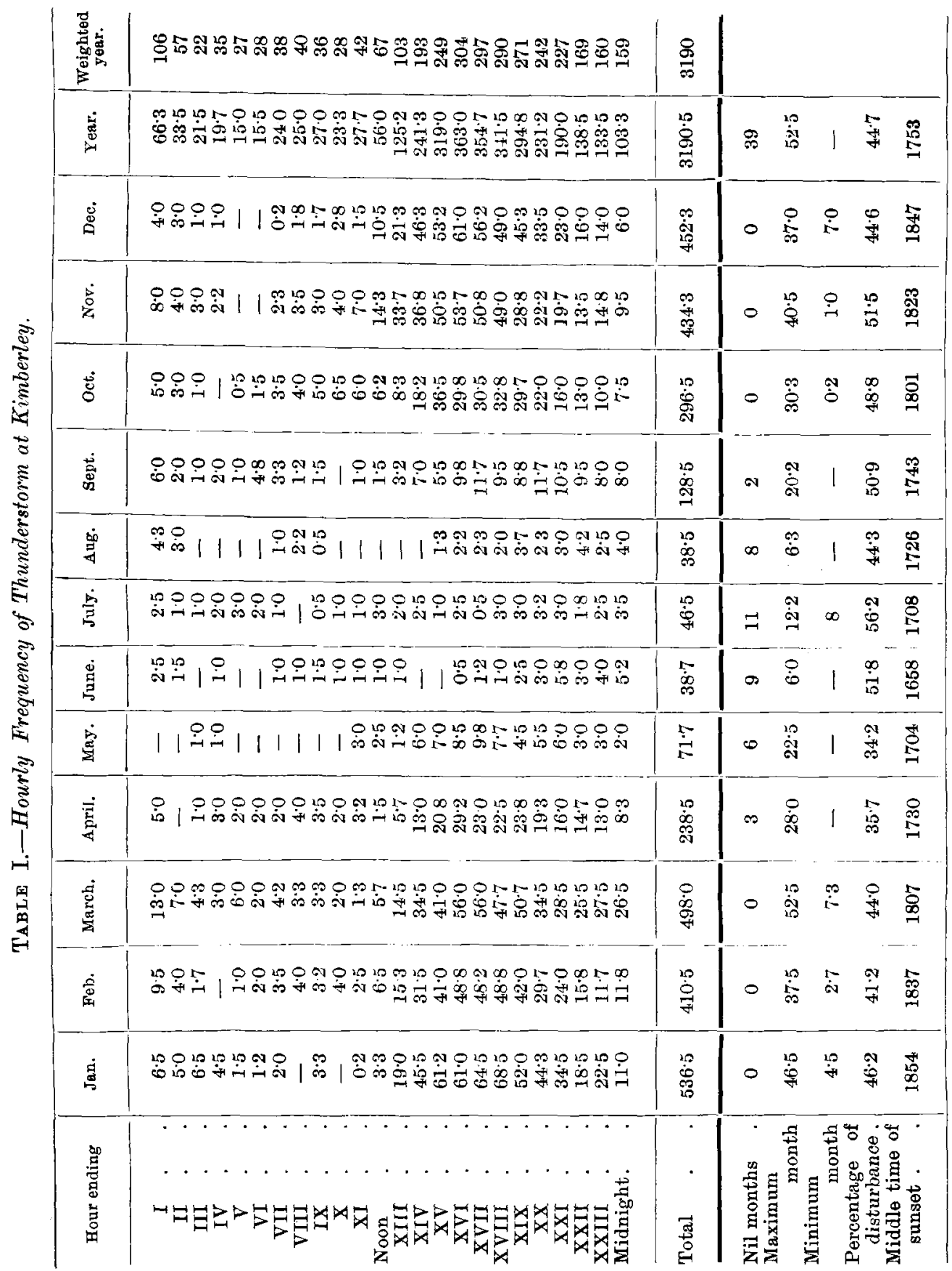


Some Statistics of Thunder and Lightning at Kimberley.

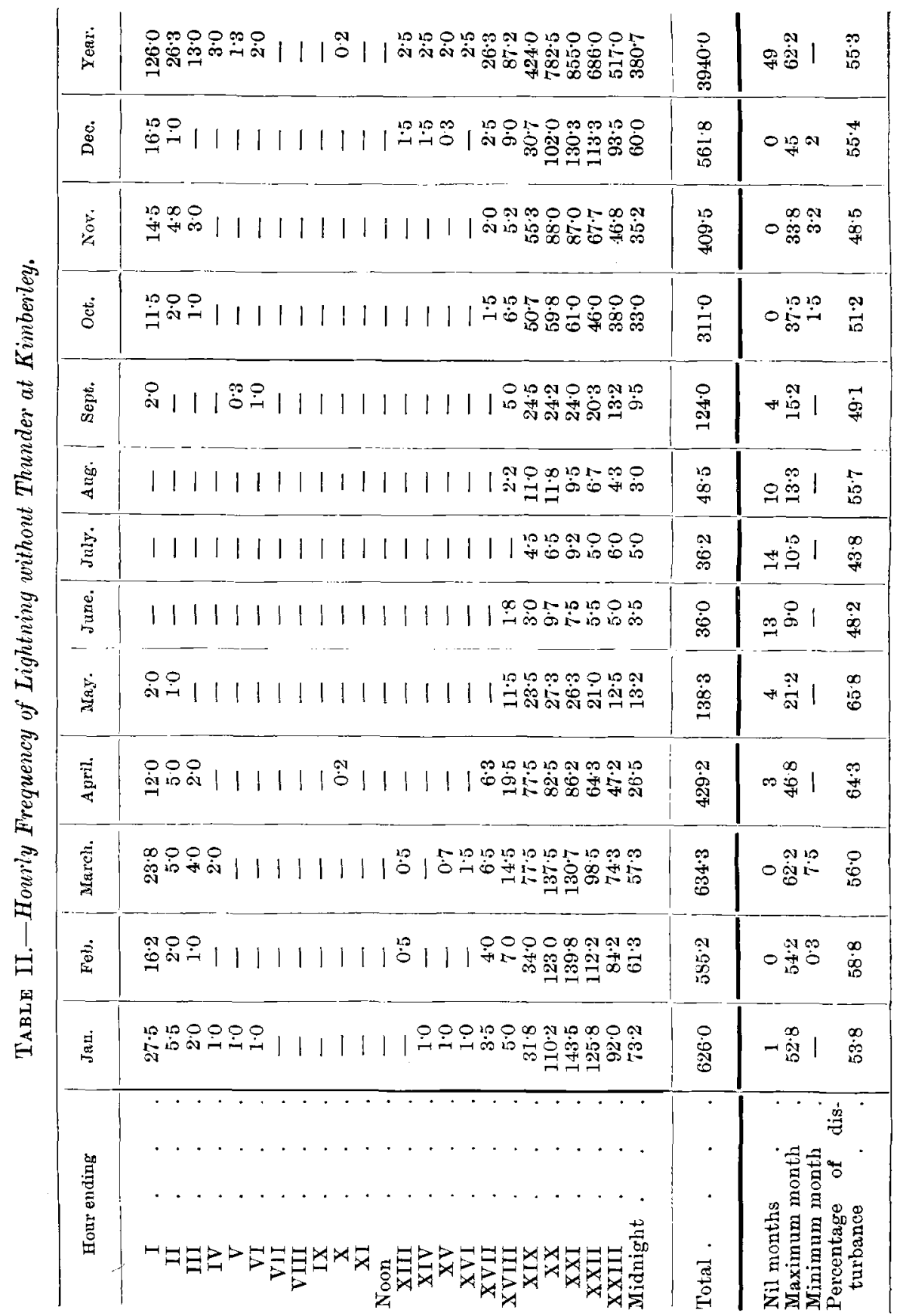




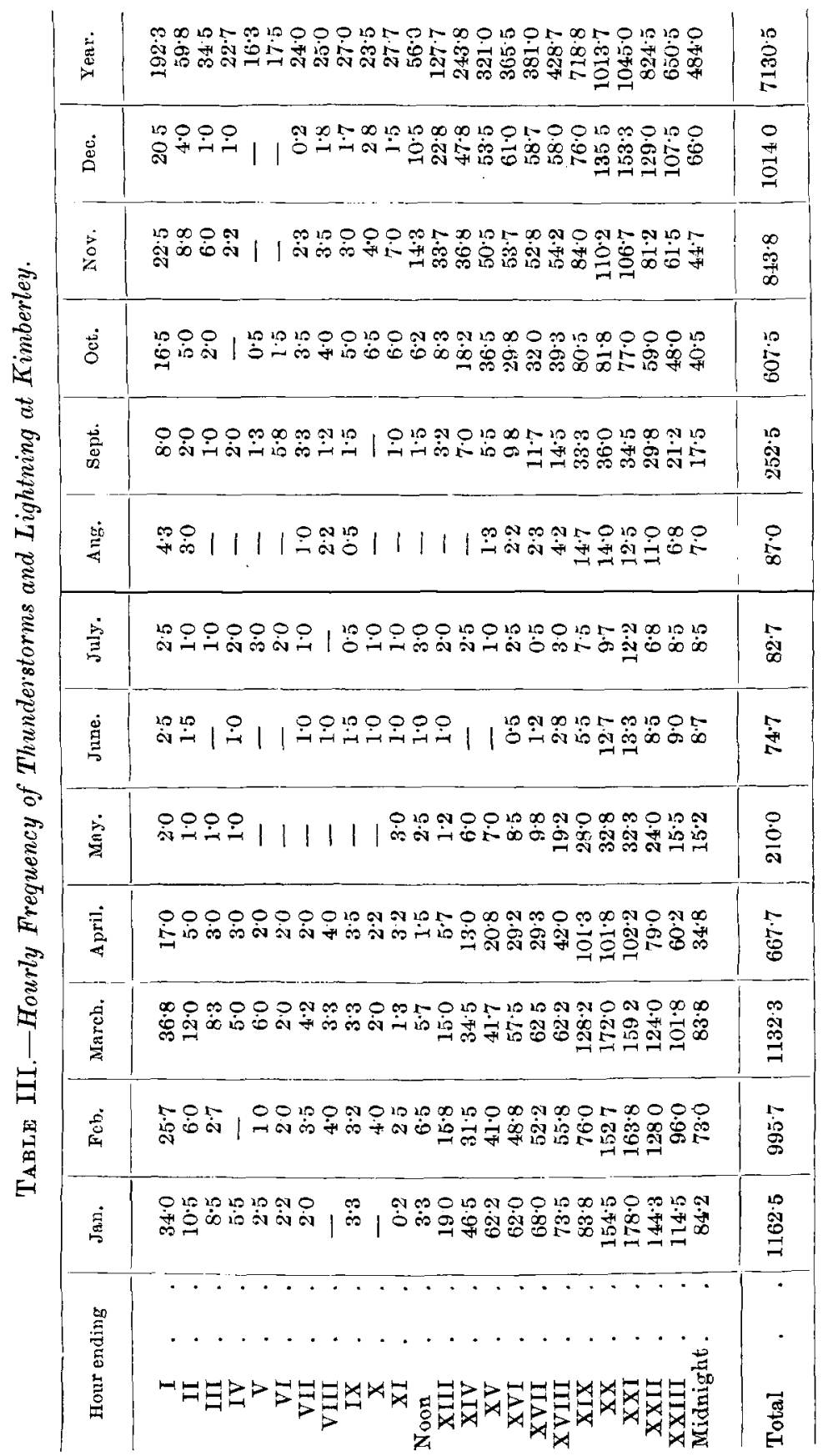


Some Statistics of Thunder and Lightning at Kimberley.

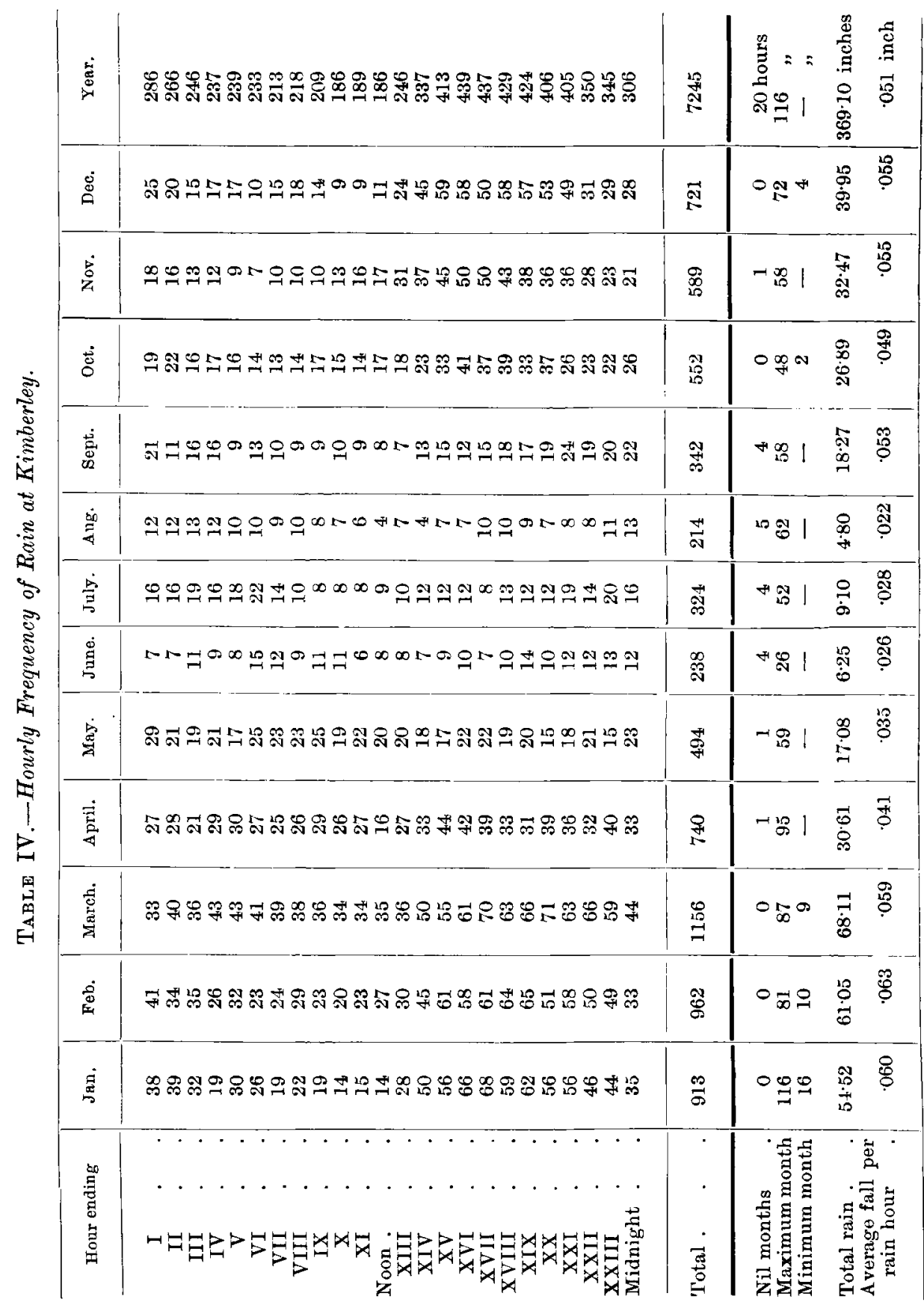


possibly of some use to airmen. Yet it may be of interest to note that Clement Ley claimed ('Met. Mag.,' 1876) that the thunderstorms of Westeru Europe are divisible into three distinct classes. A bercromby claimed (B.A. 'Report,' 1887) that there are at least three. Sir Napier Shaw remarks ('Forecasting Weather,' 1911, p. 293) that "the conditions under which thunderstorms should be forecasted are as various as the types of thunderstorms themselves." Clement Ley put it in this way :

"Those of the first class predominate in the winter months. They are far the most numerous on the western shores of Europe. They occur with low, or very low, barometrical pressure, and most commonly with steep gradients and strong winds, and are almost confined to the southern segments of depressions. They rarely take place when there is any very great difference between the direction of the upper and under currents. They are equally common by night and by day. The altitude of the storm clouds in this class is seldom so great as in the other two classes. Hail or snow frequently accompanies them. They are eminently local, and may, I think, be conveniently distinguished as thunder-squalls.

"Storms of the second type are very rare, except in the warmer months. They are least common upon our western coasts. They predominate with light winds, with moderately low pressure, and in the southern segments of depressions, but they are not at all particular as to the amount, or as to the distribution of pressure. They are local in character, but may be very severe. They occur almost exclusively by day. Their formation may often be readily watched; cumulus, frequently under a sky devoid of upper cloud, swells ot cumulonus; the summit of the latter assumes the cirri-form aspect, and a massive local nimbus is developed. I would denominate them thundershowers.

"The third class are thunderstorms, par excellence. They belong to the warm season. They are remarkably rare on our extreme western coasts. . . They are most common . . . when the isobars show local irregularities. But their most distinctive characteristic is the presence of an extensive and generally rapid southerly upper current (with more or less antagonistic surface winds) carrying cumulo-stratus over a wide area, especially to the northward and eastward of the storms. Storms of this class are as common by night as by day. They are usually less local than the others. They travel at a great altitude, are often exceedingly intense, and afford the grandest electrical display, but are productive of remarkably few accidents in proportion to the number of discharges. Their first development can rarely be watched to advantage; but the process appears to be the reverse of that which occurs in the 'thunder-showers,' the aggregation commencing in the higher regions of the atmosphere, and being propagated downwards."

Comparing this account with my statistics, it would seem that Kimberley 
winter thuuderstorms conform in some respects to Ley's first class; those of the other seasons more to that of his second class. Both divisions of the year, however, have storms which have points of resemblance to his third class. But these are details which I hope to discuss at some more favourable time.

A phenomenon of interest is the "smell" of a thunderstorm. This I have only observed once in Kimberley, and that strongly. European meteorological literature of the seventeenth and eighteenth centuries has many allusions to the "sulphureous smell" of lightning, especially when anything was struck; and the observation goes back even to the time of Homer (Odysey, XII). Before the time of Franklin theorists had, because of this odour, attributed lightning to the "breath of pyrites." 